that the alimentary canal and rectum were structures completed later in derelopment; that is, that other structures of the body were perfectly developed before the alimentary canal and rectum. That is preciscly the condition I have noticed in children. As shewn the condition results from this abnormal state of the alimentary canal. Tlis condition called indigestion is very common among neurotic and degenerate children. Neither neurologists or clinicians view it as a local condition. I believe that probably food is taken by the child which does not assimilate in the alimentary canal; hence, the small intestine does not perform its function and markedly furred tongue results. I have frequently seen this condition occur as often as four times yearly in a child. While food has a good deal to do with it, the assimilative and excretory organs do not harmonize in their action and constipation results. I do agree with Dr. Fletcher in regard to the treatment of these conditions. Jocal treatment will help greatly in clearing up the tongue, especially after the alimentary canal has been put in normal condition. Seraping the tongue may be done well, either with an instrument male for the purpose or with a tiff tooth-brush. Stimulation has most to do with the results. Frequent clearing up of the tongue results after brushing and stimulating it into a healthy condition.

Dr. G. V. I. Brows, Milwaukee. Wis.-It seems to me the essayist has given us a partial proof. What he says concern. ing the eflects of moutr-breathing upon the mucous membrane of the tongue is true in a measure, but if it were entirely true I think we would notice greater changes in the structure of that membrane in patients who are chronic mouth-breathers. While there are quite small changes in the mucous membrane. particularly in the nasal passages, that of the mouth is not materially altered, so far as its permanent form is concerned. $I$ think you all know that I am rather partial to the use of hydrogen dioxid to prepare the mucous membrane for the action of the antiseptic which you are going to use. You may not: depend upon the dinxid as an antiseptic per se, but there can be no difference of opinion as to the value of preparing the mucous membrane by using that and then following with any germicide solution. In the treatment of patients with cleft palate and other operations of the mouth, the cleansing of the mouth every half-hour, in addition to repeated washing through the nose, perhaps once or twice a day, is a matter of vital importance, and is beneficial in two different ways: One is that the effect of the germicide used is constructive to the mucous membrane, and serves on the other hand to destroy the poisonous effects of the use of the nermicide which is of a nature to be destructive upon living tissue of any kind, so I have come to use the dioxid, a 3 per cent. solution, and carbolic acid alternately, using one each half-hour, and getting good results in that way.

J). A. E. BaLdwix, Chicago-I have little to say, only that I was glad to listen to the paper, and it shows a line of investigation that could be made productive of results. I have long thought that the nucous membrane of the mouth is perhaps more pathognomonic than we have given it, credit for, but how far the investigation, as given in the paper. turns that way, I an not prepared to say. I have in a quiet way followed the investigntion as carefully as possible in the mucous membrane of the mouths of my patients, observing them very carefully, but so far $I$ have obtained no results that I feel would be proper to present before this Section.

Duration of Pregnancy.-Aceording to the German laws the maximum duration of pregnancy is estimated at 302 days. Winckel has been reviewing the statistics of the Dresden and Munich maternities and finds that 1007 children are recorderl among the 30,500 births during the last thirty years. who measured 48 to $52 \mathrm{~cm}$. in length and weighed $4000 \mathrm{gm}$. Of this number 233 or .4 per cent. were born after the pregnaney had lasted from 303 to 336 days, showing that in case of unusually large ehildren the duration of the pregnancy is longer than the laws admit. $\mathrm{He}$ mentions that none of the children ever weighed as much as $6 \mathrm{~kg}$. at birth, and none at Dresden during the last eleven years weighed even $5 \mathrm{~kg}$.-Sammlung Klin. Tortraege, 29.?.

\section{A CONTRIBUTION TO THE SURGERY OF THE KIDNEY.}

\section{TWO CASES OF DISEASE OF THE KIDNEY SIMULATING} GALL-STONES.*

J3AYARI) HOLMES, M.D.

Professor of Surgery in the University of Illinois; Surgeon to the Baptist Hospital.

$$
\text { CIIICAGo. }
$$

The surgery of the kidney is much neglected in general practice on account of the difficulties of diagnosis which the surgical diseases of this organ present. The organ itself is hidden in the back. Its exploration through a mid-abdominal incision is unsatisfactory. The urine does not always present a suggestion of the condition of the kidney. The symptoms often lead the physician astray. Two such cases in my own practice seem to me worthy of record as a warning.

When we approach any diseased abdomen, our attention is fixed more or less intently on certain luminous spots, toward one or more of which the symptoms course or the findings almost inevitably point. The spots are the appendix, the gall-bladder, the pylorus, the kidneys and the appendages of the uterus. When we analyze the symptoms and findings of typical cases, there is little danger of error, but in atypical cases, such as the two which I have chosen to present, the diagnosis is very uncertain even after the closest observation. I hope that you will not be wearied by this simple method of presentation. for I have always found the recital of well-studied cases of the greatest practical value.

Mrs. C., 35 years old, was born in New England and educated in one of the colleges for women. She had no sickness of any account during her childhood, but as adolescence came on, she had painful menstruation and became rather nervous and hyperesthetic, but not to any serious extent. After graduation she went to the Sandwich Islands to teach. She married there and returned to the States, where a child was born in 1895 . This confinement took place in Philadelphia under competent assistance, but there is evidence in the history there was some puerperal infection of a low grade, which persisted a rather long time. After the confinement, at intervals of two or three months and rarely at intervals of ten days or two weeks, the patient suffered attacks of abdominal pain accompanied by considerable rise of temperature and rarely by vomiting. These attacks lasted only a few hours each time. The pain began in the pyloric region and extended through the back and both shoulders. There was tenderness under McBurney's point during one of the attacks, and a diagnosis of appendicitis was made. In one of the attacks a tumor was felt in the same region, and this time a diagnosis of wandering kidney was made by another physician. After these attacks there was a gradually falling temperature and considerable prostration. The patient had been put on a restricted diet without effect. She had tried hydropathic treatment and a vegetarian diet without any modification in the frequency or the severity of the attacks.

In June, 1899, she left the Sandwich Islands and came to Chicago under my treatment. I found the patient a rery intellectual woman of nervous, sanguine temperament and a New England conscience. She weighed 125 pounds. Her history was given clearly, explicitly and without bias. On examination, I found a perfectly dereloped chest and normal heart and lungs. The apex-

\footnotetext{
* Read before the Tri-State Medical Society, April 4, 1901.
} 
beat, however, was three inches from the middle line, indicating a moderate enlargement. The blood showed a normal proportion of red and white corpuscles, but the hemoglobin was only 65 per cent. Malarial organisms were found in abundance. There were many floating black particles in the blood, of unknown significance. The urine was slightly diminished in quantity and in normal constituents- 18 to 22 grams of urea a daybut although frequent examinations were made, there were never any abnormal constituents found. In examining the abdomen, both with and without chloroform anesthesia, no tumor nor abnormality was discovered.

The patient was put on antimalarial treatment, consisting of mild laxatives, a light diet, large doses of quinin, 20 grains six hours before the appearance of the slight rise of temperature, $99.5 \mathrm{~F}$., followed by arsenic for two weeks. This rise was discovered by taking the temperature every half hour during waking hours. The organisms were gone by the end of a week. During the next few months the blood was repeatedly examined, but no malarial organisms again discovered. The hemoglobin rose gradually to 85 per cent.

There were no attacks of pain during the first few weeks she was under my care, but one morning at the end of two months she sent for me in great haste, and I found her suffering moderately from pain in the abdomen, back and shoulders. Her temperature was only $99 \mathrm{~F}$., the pulse moderately accelerated. The patient was not anxious or fearful and willingly allowed protracted examination before morphin was given. Now for the first time a tumor in the region of the gallbladder was easily outlined. It was not movable, but clung to the lower border of the liver and moved with each inspiration and expiration. It was moderately tender on pressure. No other signs or symptoms were elicited. A small hypodermic of morphin was given and the hot water-bag placed over the liver. In two hours the pain and tumor had both disappeared. The next attack came on only a few days later, after a hearty meal. It resembled the first attack in every particular, except that it began with vomiting. The tumor appeared again and disappeared with a liquid movement of the bowels. The third attack came on in October, and was more severe and long lasting than either of the others. This time I had Dr. George W. Webster in consultation. He saw the patient alone. The tumor in the region of the gall-bladder was present as before, but now for the first time there was distinct jaundice and the urine contained an unmistakable circle of bile. The case was thought from the first to be one of stone in the cystic duct, for the following reasons: 1, pain in the region of the back and shoulders; 2 , tumor in the region of the gall-bladder; 3 , absence of all evidence of renal disease; 4, clinical history of biliary calculus. With this history and the advice of Dr. Webster, I deemed it best to remove the stone.

After the usual preparations and under chloroform anesthesia, she was operated on November 30 . Her temperature was normal and her pulse 88 before the operation. An incision three inches long was made along the right border of the rectus muscle and the abdomen explored. The gall-bladder was of normal appearance and thickness and contained no calculus. The right renal region was filled by a cyst-like mass somewhat larger than a kidney. The ureter was of normal size and feeling. The peritoneum was opened over the kidney and behind the colon and attached to the depressed peritoneal edges of the abdominal wound by
The small amount of fat over the cyst was pushed away and the tumor pulled out through the abdominal wound and examined. It was found to be a cystic kidney, the outer surface of which looked like an ovarian cyst. The kidney substance was gone, except at a point near the lower pole, where a mass remained as big as the ball of the thumb. The wound was protected and the cyst opened. It was found to involve all the calices and the pelvis. The ureter opened out of it by a short turn. There appeared to me no way by which the small amount of kidney tissue could be saved and the ureter made effective. Therefore the artery and veins were separated from the ureter and ligated with strong, braided silk. The kidney was removed and the ureter pulled out of the wound as far as possible and cut off. The mucous membrane was turned in and the muscular and fibrous coats sewed tight together with fine silk. The stump was then dropped. On account of fear of infection from the interior of the cystic kidney which had been opened over the wound. I decided to pack the cavity with gauze containing a little iodoform. The ends of the abdominal wound were closed, leaving only a small opening for drainage. The operation lasted an hour and a half and was borne without event.

The temperature rose four hours after the operation to $99.6 \mathrm{~F}$., and there was considerable pain and vomiting. During the following few days the urine was quite scanty, but it contained no abnormal constituents. The temperature never rose above $100 \mathrm{~F}$. and the convalescence was perfectly normal. The packing was removed from the wound within a week, but the cavity became infected and did not close until six weeks later. Warning was given by a sharp chill and rise of temperature to $10 \pm \mathrm{F}$, and the silk ligature on the renal artery was removed under cocain anesthesia. The urine had gradually and steadily increased in quantity until it reached 1000 e.c., and until the urea rose to 18 to 20 grams a day. During the convalescence there was a sharp attack of pain resembling the old paroxysms, but since that time, almost a year and a half; she has had no pain and no sickness. The urea has steadily increased and the patient has enjoyed almost perfect health. She has led an active student and literary life.

Mrs. M., 40 years old, of New England stock, was born and spent most of her early life in the tropics. She was always very active mentally and physically, but was never very strong. She weighed about 120 pounds. She was never ill except when her only child was born eight years ago. The labor was difficult.

In 1889 she had an attack of colic with fever and jaundice and was ill several days. Again, a few years later, while in Europe, she had a somewhat similar attack without jaundice. In 1898 she had several attacks of severe pain in the abdomen. During these attacks I attended her. The pain was severe paroxysmal, lasting fifteen to thirty seconds, with about an equal interval. she preferred a sitting position, bent over on her knees, with head and shoulders turned down. The greatest pain was in the back and shoulders, with none in the legs or vulva. The muscles on the right side of the abdomen were rigid and examination was difficult. A few drops of chloroform in olive-oil usually relieved the pain at once. On a number of occasions she had the sudden relief characteristic of displaced mechanical obstruction. The urine was frequently examined, but no abnormal constituents were found. There was no bile. A provisional diagnosis of gall-stones was made. The A provisional diagnosis of gall-stones was made. The 
treatment. There was a long interval, several months, of apparent relief, but during this time she always remembered her side. About October, 1900, she was taken with a most severe attack and for the first time a distinct tumor was felt in the region of the gall-bladder. It was hard, round, immovable and painful. A few whiffs of chloroform were given to facilitate examination, and after waking up the pain was gone. The next day the tumor could not be felt. During the Christmas vacation a very protracted attack was suffered and this time there was no complete relief for a week. Severe sharp attacks followed in quick succession after her return to the city, and in two or three, the tumor in the region of the gall-bladder was unmistakably felt. In one attack, the pain disappeared during palpation of the abdomen. Her temperature during these paroxysms rose to $99 \mathrm{~F}$., but once or twice a degree higher. The urine was uniformly acid, of rather large quantity and contained 2.5 to 3 per cent. of urea. There were never any abnormal constituents.

With the following indications and diagnosis, which I copy verbatim from the notes of her history sheet made before operation, she entered the Baptist Hospital for operation Jan. 14, 1901.

$$
\text { INDIC:ATIONS AND SYMPTOMS. }
$$

1. History of abdominal pain, region of gall-bladder, radiating into back (and shoulders), certainly not into labia or legs. Duration six or eight years.

2. These pains severe, often light or simply threatening; when severe, terminating suddenly with complete relief.

3. Rigidity of muscles over right side of abdomen continuing even after the paroxysms of pain have subsided.

4. Tumor felt on at least three separate occasions in region of gall-bladder. Unfortunately no history or record of recognition of kidney at same time and separate from it.

5. No tumor or tenderness over appendix or over course of ureter. or in pelvis.

6. No tumor or tenderness over pancreas.

7. No tympanites. Rumbling of gas in bowels during and after attack, with no appreciable rrlief from pain or difference in character after paroxysm.

8. No fluid in peritoneal carity.

9. No abnormal constituents in urine; acid.

10. No dilatation or hypertrophy of heart as in stone in kidney.

11. No evidence of tuberculosis in examination or history.

12. Low temperature, 99 to 100 ; with subnormal temperature of 97.5 .

13. No vomiting, and enly once or twice "sick headache."

14. No disorders of bowels, movements a little tardy, no diarrhea after paroxysm.

15. No jaundice (except in 1889).

\section{DIAGNOSIS.}

The diagnosis lies between 1, gall-bladder disease; 2, appendicitis; 3 , mechanical obstruction of kidney; 4, tubercular peritonitis; 5 , obstruction at hepatic flexion of colon; 6 , tumor in this region: and lastly, gatralgia or hysteria.

The disease or condition is of long duration, 2 to 8 years; no suppuration, temperrture 99 to 100 ; probably mechanical. stopping the discharge of some viscus and the peristaltic action of some set of muscles.

The usual preparations were made and with chloroform anesthesia the abdomen was opened on the right border of the rectus muscle. The gall-bladder was found empty of stone and normal in appearance. The right kidney was movable and directly under the gall-bladder, but easily brought into the middle-line under the umbilicus. After thorough examination of the pylorus, the appendix and the right ovary, the floating kidney was considered the only adequate cause of pain; it was fasiened hark in its nlane in tho nano? mannon mhe location was approached by a long, curved incision, the kidney denuded of fat and pushed back so as to button through the inner fascia of the quadratus. It was fastened to the fascia by a double row of interrupted long-lasting catgut stitches. Both wounds were then closed in layers.

The patient made a perfect recovery except for one alarming complication. During the four weeks she was in the hospital, she had three attacks of pain similar to the pain she formerly suffered. Since that time she has been entirely free from pain. The kidney remains in place and she has resumed her very active life.

\section{THE GYNECOLOGICAL AND OBSTETRICAI, SIGNIFICANCE OF GIRLHOOD. \\ HENRY P. NEWMAN, A.M., M.D. \\ CHJCAgo.}

I have recently received a letter from Dr. George Engelmann, of Boston, announcing his intention of reading a paper before the Gynecological and Obstetrical Section at the June meeting of the Americal Medical Association, on "The Causes of the Increasing Sterility of American Women," and stating his conviction that the subject is of vital importance and needs investigating. The same authority, as President of the American Gynecological Society, made an elaborate address last year upon a very nearly related topic: "The American Girl of To-day," and aroused much interest in his carefully prepared and somewhat startling statisties. It would appear from his researches, and in these he was assisted by prominent educators, teachers in young women's colleges and normal schools and by the heads of mercantile houses where women are employed, that the absolutely normal, healthy girl is exceedingly rare. It is evident that for her own sake as a future mother and for the sake of the race which is to come of her that we should do something to better the conditions which threaten her maternal functions.

The lack of fertility is not the only evil. The need is not so much for larger as for better families. The higher you go in the scale of animal value and intelligence the scarcer become the progeny. We want a better physical heritage for the few. It is the right of each individual to be perfectly born and generously nourished at a healthy mother's breast. A perfectly just and apparently simple proposition, but one requiring the united effort of our entire domestic, social and scientific systems. It has been proposed that the obstetrician be given charge of the whole period of gestation. But this is not enough. Too often he will find threatening lesions, infections, inflammations, malformations and malpositions already existing and will feel that to be successful with his case he should have had an oversight over the years of girlhood in which so much mischief was done.

The case-books of our specialists in gynecology and obstetrics and the records of teachers and employers of young girls go to show that the period between childhood and womanhood is not all what it should be. This period in which nature is concentrating all her energies upon the development of the generative organs ind the establishment of their physiological functions is ordinarily that in which greatest demand is made lipon the vital forces of the girl by the exigencies of our mi dern social and educational systems.

Her mental and nervous forces are taxed to the utmost by the ambitions of the study room, and the transitions User on $06 / 14 / 2015$ to high and normal schools; she is over- 